\title{
Sheet-beam Electron Gun Design for Millimeter and Sub-millimeter Wave Vacuum Electronic Sources
}

\author{
B.G. Danly \\ Electronics Science \& Technology \\ Division, Code 6841 \\ U.S. Naval Research Laboratory \\ 4555 Overlook Ave., SW \\ Washington, DC 20375 \\ danly@nrl.navy.mil
}

\author{
J.J. Petillo \\ Science Applications International \\ Corporation \\ Suite 130 \\ 20 Burlington Mall Rd \\ Burlington, MA 01803
}

\author{
J.X. Qiu \& B. Levush \\ Vacuum Electronics Branch \\ Code 6840 \\ U.S. Naval Research Laboratory \\ 4555 Overlook Ave., SW \\ Washington, DC 20375
}

\begin{abstract}
We investigate the application of sheet beams to slowwave sources as a means to increase output power. Our interest is for compact vacuum electronic devices in the millimeter and submillimeter regimes. We consider previous work done on orotrons, clinitrons \& backward wave oscillators, and investigate methods to enhance operation into the submillimeter region of the spectrum We use MICHELLE to model $\sim 40$ micron thin sheet beams for such devices.
\end{abstract}

Keywords: Sheet beams; sheet beam sources; sheet beam guns; orotron, clinitron; backward wave oscillators, sources, sheet beam formation; beam optics; MICHELLE; Voyager.

\section{Introduction}

Compact millimeter and submillimeter wave vacuum electronic sources have a variety of limitations which prevent them from achieving higher output powers. In some cases the limitation in output power can be alleviated through the use of spatially distributed or sheet electron beams. In slowwave sources such as klystrons and traveling wave tubes (TWTs) the use of sheet beams and appropriate circuits can, at least in principle, be utilized to increase power of the device. Several efforts are now underway with that objective in mind (see, for example, [1]). For vacuum electronic sources operating in the upper millimeter wave bands, such as the orotrons [2,3] (or Smith-Purcell freeelectron laser), clinotrons [4], and backward wave oscillators (BWOs) similar performance increases can be expected, and in fact such approaches certainly play a role in the present day achievement of power for these devices. Nevertheless, operation of these devices into the submillimeter portion of the spectrum has been limited by a number of technical challenges, including the electron beam generation and limitations on beam current density, as well as manufacturing issues for the slowwave interaction structure $[5,6]$.

\section{Background}

The design of a sheet beam electron gun is underway at NRL for application to a MM/SMM wave orotron. The gun design parameters are for a beam of $3 \mathrm{~mm}$ by $40 \mu \mathrm{m}$ (aspect ratio of 75:1), and a total current of 50 - $100 \mathrm{~mA}$. The smaller of these dimensions is set by the requirement that the beam thickness be smaller than the transverse scale length of $L_{\perp}=\gamma \beta \lambda / 2 \pi$. In principle such a beam thickness can be achieved with either focusing gun design of high area convergence or with a gun design of negligible area covergence and operation in an immersed focusing field. The preliminary gun design utilizes an immersed flow design with a flat rectangular cathode. The MICHELLE gun code has been used to model the sheet beam formation and transport; results from a preliminary run are shown in Fig. 1. Further results from this design effort will be presented.

\section{Applications}

The maximum design voltage for this electron gun is 15 $\mathrm{kV}$; at this voltage the beam current is $100 \mathrm{~mA}$ and the maximum field stress is approximately $82 \mathrm{kV} / \mathrm{cm}$. The cathode current density is approximately $83 \mathrm{~A} / \mathrm{cm} 2$, necessitating the use of a $\mathrm{LaB6}$ or CeB6 emitter. Such emitters are available commercially [7]. The focusing field for the gun is assumed to be $8 \mathrm{kG}$, and will be provided by a Magic sphere permanent magnet, previously manufactured under an ARL contract with CPI-CMP.

\section{References}

1. B.E. Carlsten. Modal analysis and gain calculations for a sheet electron beam in a ridged waveguide slowwave structure. Phys. Plasmas, 9(12):5088-5096, 2002.

2. F. S. Rusin and G. D. Bogomolov. Orotron - an electronic oscillator with an open resonator and reflecting grating. Proc. IEEE, pages 720-722, 1969.

3. K. Mizuno, S. Ono, and Y. Shibata. Two different mode interactions in an electron tube with a FabryPerot resonator - the ledatron. IEEE Trans. Electron Dev., 20(8):749-752, 1973.

4. K. Schunemann and D.M. Vavriv. Theory of the clinotron: a grating backward-wave oscillator with 
inclined electron beam. IEEE Trans. Electron Dev., 46(11):2245-2252, 1999.

5. V.L. Bratman, B.S. Dumesh, A.E. Fedotov, Yu.A. Grishin, and F.S. Rusin. Broadband orotron operation at millimeter and submillimeter waves. Int. J. Infrared and Millimeter Waves, 23(11):1595-1601, 2002.

6. R.L. Ives, M. Caplan, C. Kory, T. Robinson, R. Wilcox, J. Neilson, S. Schwartzkopf, and R.
Witherspoon. Design and test of a submillimeter-wave backward wave oscillator. In Sixth International Vacuum Electronics Conference IVEC2005, pages 167-170, 2005.

7. Applied Physics Technologies, Inc., private communication.

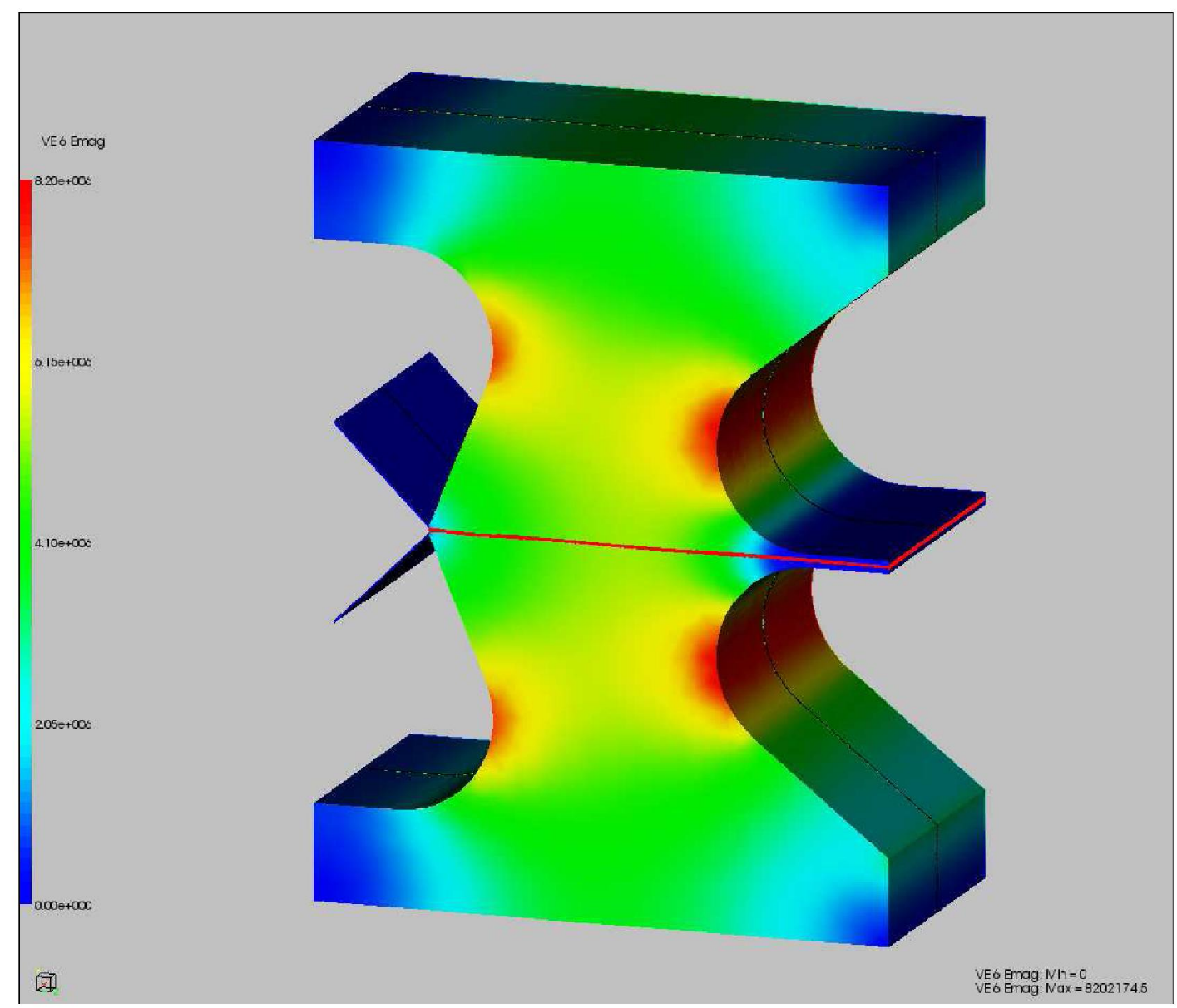

Figure 1: MICHELLE Code run of sheet beam transport in $8 \mathrm{kG}$ immersed field 